\title{
Similar behaviors of natural ELF/VLF ionospheric emissions and transmitter signals over seismic Adriatic regions
}

\author{
M. Y. Boudjada ${ }^{1}$, K. Schwingenschuh ${ }^{1}$, H. K. Biernat ${ }^{1,2,3}$, J. J. Berthelier ${ }^{4}$, J. Blecki ${ }^{5}$, M. Parrot ${ }^{6}$, M. Stachel ${ }^{1}$, \\ Ö. Aydogar ${ }^{1}$, G. Stangl ${ }^{7}$, and J. Weingrill ${ }^{1}$ \\ ${ }^{1}$ Space Research Institute, Austrian Academy of Sciences, Graz, Austria \\ ${ }^{2}$ Institute of Physics, Department of Theoretical Physics, Karl-Franzens-University Graz, Austria \\ ${ }^{3}$ Institute of Physics, Department of Geophysics, Astrophysics and Meteorology, Karl-Franzens-University Graz, Austria \\ ${ }^{4}$ Centre d'Etude des Environnements Terrestre et Planétaires, Observatoire de Saint-Maur, France \\ ${ }^{5}$ Space Research Centre PAS, Warsaw, Poland \\ ${ }^{6}$ Laboratoire de Physique et Chimie de l'Environnement, Orléans, France \\ ${ }^{7}$ Federal Office of Metrology and Surveying, Vienna, Austria
}

Received: 18 July 2008 - Revised: 26 September 2008 - Accepted: 29 September 2008 - Published: 24 November 2008

\begin{abstract}
We report on the analysis of ELF/VLF emissions observed by the Instrument Champ Electrique (ICE) experiment onboard the DEMETER micro-satellite. We consider principally selected seismic events reported by Molchanov et al. (2006). These authors studied the VLF signals radiated by ground transmitters and received on board the DEMETER micro-satellite. They revealed a drop of the signals (scattering spot) connected with the occurrence of large earthquakes. In our investigations, we proceed to a spectral analysis of ICE observations with the aim to find if the natural ionospheric VLF/ELF emissions show, or not, a similar "drop;; in the intensity as it is the case of the VLF transmitter signal. We combine our results with those of Molchanov et al. (2006), and we discuss the origin of such interesting ionospheric features in the frame of the investigation of the pre-seismic electromagnetic emissions. We show that the geomagnetic activity is a key parameter which could disturb the natural VLF ionospheric emissions, and also the transmitter signal. We find that it is not possible to conclude the presence, or not, of a preseismic effect when the Kp-index is higher than one.
\end{abstract}

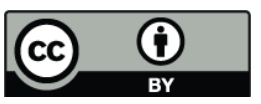

Correspondence to: M. Y. Boudjada (mohammed.boudjada@oeaw.ac.at)

\section{Introduction}

Since more than twenty years detailed observations of electromagnetic signals occurring before seismic events have been reported. Such precursors emissions have been found to cover a large frequency spectrum: ULF (Fraser-Smith et al., 1990; Molchanov et al., 1992; Hayakawa et al., 1996a), ELF/VLF (Gokhberg et al., 1982; Parrot and Lefeuvre, 1985), LF (Bella et al., 1998), and HF (Warwick et al., 1982). These first investigations had been supported by other observations and laboratory experiments as reviewed in Parrot (1995), Hayakawa and Molchanov (2002) and Molchanov and Hayakawa (2008).

\subsection{Artificial signals as a sounder of seismic activity}

One important aspect of the seismic electromagnetic research is the analysis of the ionospheric disturbances observed principally over the seismic regions (Pulinets and Boyarchuk, 2004). These disturbances were mainly derived from the ionosonde electron density measurements. However this technique is found to be limited and difficult because of the local temporal and spatial coverage of the seismic regions. This limited area coverage is resolved by the use of ground-based receivers connected to the global positioning system (GPS) which is deployed to monitor the Earth's surface deformation rates, and also to provide continuously monitoring of the ionospheric total electron content (TEC) as described by Sardon et al. (1994). The remote sensing of the ionospheric disturbances, associated to seismic

Published by Copernicus Publications on behalf of the European Geosciences Union. 
activity, have been investigated using GPS (Liu et al, 2001), space ionosonde (Pulinets, 1998), broadcasting (Biagi et al., 2001, 2004) and navigational signals (Gufeld et al., 1992, Hayakawa et al., 1996b). Except rather questionable results by satellite topside sounding, all the other ones were obtained by observations on the ground and consequently they were related to more or less local conditions. The registration of VLF radio signals has provided interesting information on the disturbances in the upper atmosphere-lower ionosphere boundary. However the spatial area of the analysis was limited to a narrow zone along the path between the transmitter and the receiver (Molchanov and Hayakawa, 1998; Rozhnoi et al., 2004; Maekawa et al., 2006).

\subsection{Transmitter signal disturbances over seismic regions}

A new method of ionospheric sounding in connection with earthquakes activity has been recently proposed by Molchanov et al. (2006). These authors used the transmitter signal of ground-based station as recorded by the electric field (Berthelier et al., 2006) and magnetic field experiments (Parrot et al., 2006) onboard DEMETER microsatellite (Cussac et al., 2006). The investigation of intensity levels of transmitter signals allowed us to find that these ground signals decreased few days before the seismic event occurrence (Molchanov et al., 2006). This result has been further confirmed in recent papers by Rozhnoi et al. (2007), Muto et al. (2008), and Slominska et al. (2008). The first paper was based on the monitoring of VLF/LF signals recorded by ground-based station (Kamchatka, Russia) and others by DEMETER micro-satellite. Authors considered seismic events which occurred in Japan-Kamchatka area in November-December 2004, and July-September 2005. Rozhnoi et al. (2007) found clear anomalies both in the ground and in satellite data. Muto et al. (2008) followed the method proposed by Molchanov et al. (2006), and applied it to investigate Japanese earthquakes (EQs) which occurred in the period of June-August 2005. They reported significant changes in the intensity in particulary in the signal to noise ratio before the $\mathrm{EQ}$, which is considered to be a precursory ionospheric signature of the EQ. Slominska et al. (2008) discussed the modification of the VLF signals from Komsomolsk na Amure transmitter (Russia) prior to the EQ in Honshu on 16 August 2005, and also registered by DEMETER micro-satellite.

In this paper, we investigate the electric field measurements recorded by the ICE experiment, over the Adriatic seismic region, in November and December 2004. We start to describe in the next section instrumental features of the ICE experiment. In Sect. 3 we introduce and develop the basic ideas of the spectral method, the ways to derive the intensity variations of the ELF/VLF emissions, and the combination of the transmitter signal and natural ionospheric emissions. Main results are discussed in Sect. 4, and summarized in Sect. 5.

\section{Instrument Champ Electrique experiment (ICE)}

The DEMETER mission provides a first possibility to study the electromagnetic pre-seismic emissions using batteries of experiments which lead to get a more complete view of such phenomena. ICE experiment onboard DEMETER leads to perform a continuous survey of the DC and AC electric fields over a wide frequency range and with a high sensitivity in order to search for possible electrostatic and/or electromagnetic waves in the ionosphere that might be induced by seismic activity. The instrument and the onboard data processing have been designed to provide an optimum set of data in the various frequency ranges, emphasizing full characterization of the 3 components of the waves at frequencies below $1 \mathrm{kHz}$ and single axis waveform transmission and spectrum measurements at higher frequencies.

This experiment consists of 4 spherical sensors with embedded pre-amplifier electronics mounted on the ends of 4 booms. The component of the electric field is determined along the axis defined by two sensors. Any pair of sensors among the four can be used for this objective which enables the 3 components of the DC and AC vector electric field to be measured. Four frequency ranges have been defined, DC/ULF [0-15 Hz], ELF [15 Hz-1 kHz], VLF [19 Hz$20 \mathrm{kHz}]$ and HF [3.25 kHz-3.3 MHz]. The power spectrum is computed with frequency and temporal resolutions that depend on the spacecraft and ICE modes of operation. In the survey mode the power spectrum is stored with a $19.53 \mathrm{~Hz}$ frequency resolution and averaged over $2.048 \mathrm{~s}$. The average noise level is about $0.1 \mu \mathrm{V} \mathrm{m}^{-1} \mathrm{~Hz}^{-1 / 2}$ above $100 \mathrm{~Hz}$ in the ELF channel, and in most of the VLF range is in the order of $0.05 \mu \mathrm{V} \mathrm{m}^{-1} \mathrm{~Hz}^{-1 / 2}$ (Berthelier et al., 2006).

\section{Data processing}

\subsection{Dynamic spectral analysis}

Figure 1 shows dynamic spectra of ICE observations recorded on 15 November 2004, between 22:27 UT and 23:00 UT. It corresponds to the variation of the intensity versus the time (in UT) and the frequency (in $\mathrm{Hz}$ ). The high spectral resolution of the experiment (size pixel is $2.048 \mathrm{~s} \times 19.53 \mathrm{~Hz})$ leads to record the fine features which occur during one half-orbit ( $\sim 35 \mathrm{~min})$. A dynamic spectrum has 980 spectra and 1024 channels in time and frequency range, respectively. The total number of pixels for one given dynamic spectrum is about $10^{6}$ points. This huge collected information needs to be processed in the way to derive the variation of the ELF/VLF ionospheric components during each half-orbit. The observed ionospheric components are principally the hiss, the chorus, the whistlers, and the artificial signals, e.g. calibration and transmitters signals. For a given half-orbit of DEMETER satellite, the ELF/VLF components are observed before and after the equator, and in the 
invariant latitude range from $-65^{\circ}$ to $+65^{\circ}$. In the incoming sub-section, we estimate the variation of the intensity level versus the time or the frequency. The aim is to quantify the ELF/VLF activity intensity during a given half-orbit.

\subsubsection{Time profile}

Figure 1a shows the variation of the intensity level versus the time recorded on 15 November 2004 during one-half orbit. For this we consider for each spectrum the averaged intensity $\langle I(t)\rangle$ using the following relation:

$$
<I(t)>=\frac{1}{N_{f}} \sum_{i=0}^{i=1023} I(t, i),
$$

where $t$ is the observed time, $i$ is the index related to the frequency channel, and $N_{f}$ is the total number of channels.

The well-known ELF/VLF ionospheric components are observed according to Fig. 1a:

(a) Magnetospheric origin components the hiss (Hayakawa and Sazhin, 1992) and the chorus (Sazhin and Hayakawa, 1992) emissions are essentially recorded in the beginning and the end of the half-orbit in the time intervals between 22.40 UT-22.50 UT, and 22.91 UT23.08 UT, respectively. The global shape of these components shows first an increase of the emission until a maximum and followed by a decrease. One has to note that these components are the most intense emissions on the ICE dynamic spectrum. The hiss and chorus intensities are about 4 order of magnitude higher than the noise levels. This noise is mainly attained when the satellite is very close to the equatorial region as one can see in Fig. 1a around 22.76 UT.

(b) Whistler emission (Hayakawa, 1995) appears as very fast bursts which are superposed to the global variation curve. The occurrence number of whistler is increasing few dozen of minutes before and after the equator.

(c) Calibration signal: During one half-orbit, two intense signals are generated by the ICE experiment with the aim to convert the relative intensity (in $\mathrm{dB}$ ) into spectral density given in $m \mathrm{~V}^{2} \mathrm{~m}^{-2} \mathrm{~Hz}^{-1}$. These signals are clearly seen before and after the equator at about 22.65 UT and 22.85 UT, respectively.

The advantage of such an illustration is to get a quick look on the time occurrence of the observed components. However it is not possible to distinguish between the hiss and the chorus components in particular to define their corresponding respective frequency ranges.

\subsubsection{Frequency profile}

We consider the observation recorded on 15 November 2004 and we estimate the variation of the intensity level versus the
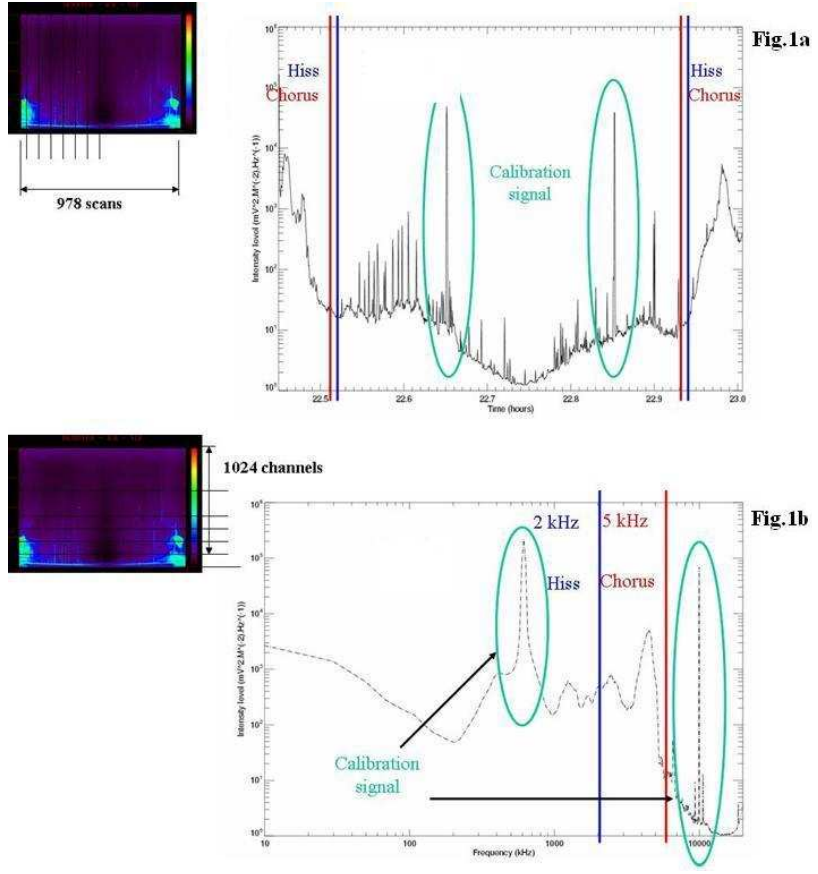

Fig. 1. Dynamic spectra of ICE experiment recorded on 15 November 2004 between 22:27 UT and 23:00 UT (left images), and the corresponding ELF/VLF intensity variations (expressed in $\mathrm{mV}^{2} \mathrm{~m}^{-2} \mathrm{~Hz}^{-1}$ ) versus the observation time (Fig. 1a) or the frequency range (Fig. 1b).

observed frequency range, from $20 \mathrm{~Hz}$ to $20 \mathrm{kHz}$. We calculate for each frequency (i.e. each channel) the variation of the intensity level during the half-orbit. This leads us to get 1024 curves associated to the observed frequency range. Then we deduce for each channel an averaged intensity $\langle I(f)\rangle$ value as:

$$
<I(f)>=\frac{1}{N_{t}} \sum_{i=0}^{i=977} I(j, f),
$$

where $f$ is the channel frequency, $j$ the index related to the time spectrum number, and $N_{t}$ the total spectrum number.

Different components are observed as one can see in Fig. 1b:

(a) The intensity level is, first, found to decrease in the frequency range from $10 \mathrm{~Hz}$ to about $200 \mathrm{~Hz}$. In this frequency interval one notes the absence of structured bursts because of low frequency resolution. This part is followed by a very strong calibration signal at about $600 \mathrm{~Hz}$ which is almost two orders of magnitudes higher than the emission at lower frequencies.

(b) The hiss and chorus emissions appear in the frequency higher than $1 \mathrm{kHz}$, showing two/three peaks of emissions followed by an abruptly decreasing, to the frequency of $10 \mathrm{kHz}$, of the intensity level. 

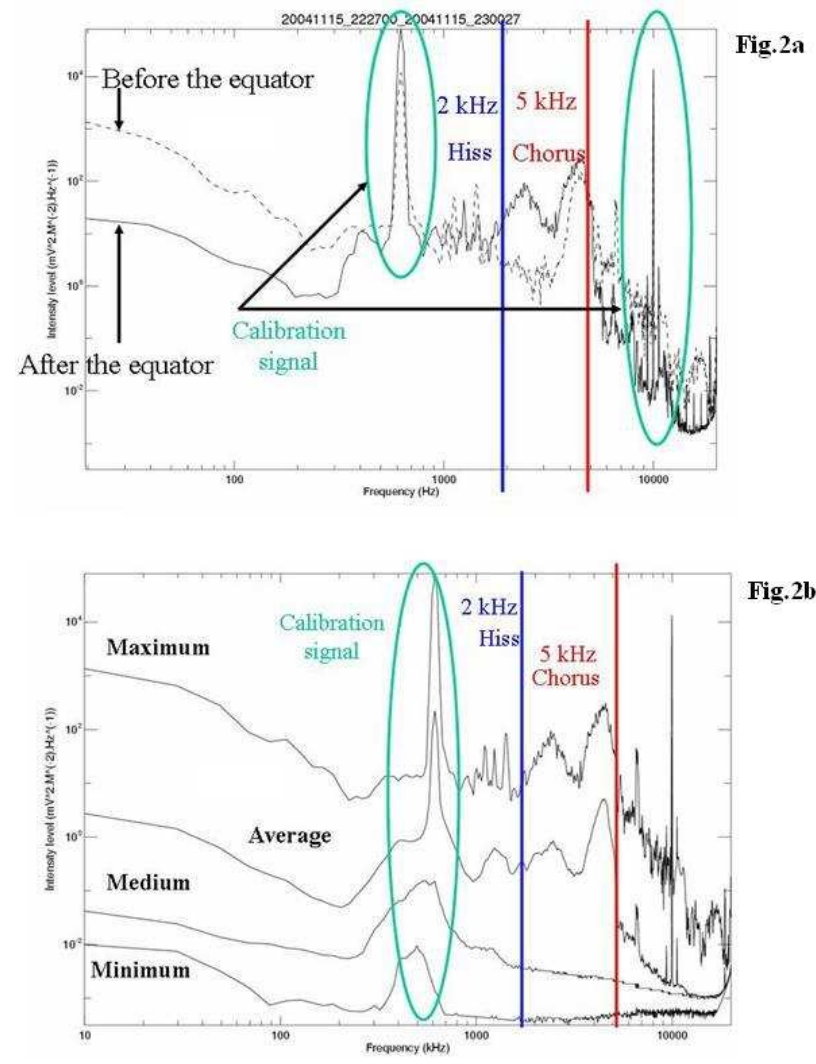

Fig. 2. ELF/VLF intensity variations versus the frequency range as recorded by ICE experiment before (dashed line) and after (full line) the equator on 15 November 2004 between 22:27 UT and 23:00 UT (Fig. 2a). Estimation of the ELF/VLF level variation versus the frequency range taking into consideration maximum, averaged, median and minimum of intensity levels for each recorded frequency channels (Fig. 2b).

(c) In the last part of the spectrum, between $10 \mathrm{kHz}$ and $20 \mathrm{kHz}$, one notes the presence of a calibration signal at frequency of $10 \mathrm{kHz}$, and also VLF transmitter signals are found to occur in the higher part of the spectrum (higher than $\sim 15 \mathrm{kHz}$ ).

One can also separate between the emissions which occur before and after the equator. Figure $2 \mathrm{a}$ shows the variation of the ELF/VLF components taking into consideration the positive and negative satellite latitudes. The intensity level is principally found to be higher, about one/two order of magnitudes, before the equator. Nevertheless in the chorus frequency range $(2 \mathrm{kHz}$ to $5 \mathrm{kHz})$ the intensity level is weak before the equator. Also three consecutive VLF transmitter signals are clearly distinguished after the equator at higher frequency $(\sim 18 \mathrm{kHz})$.

\subsubsection{Spectral envelope}

The variation of the intensity versus the frequency (as shown in Fig. 2a) can be used to estimate the spectral envelope. For this we derive the intensity variation by taking into consideration the maximum, the median and the minimum levels for one given frequency channel. Figure $2 b$ displays the four curves in the case of the event recorded on 15 November 2004, between 22:27 UT and 22:45 UT. The "maximumcurve" displays more features than the other ones. In particular one can see sub-structures between $1 \mathrm{kHz}$ and $2 \mathrm{kHz}$ which are absent on the "average-curve", and all details are nearly lost on the "medium- and minimum-curves". The "maximum-curve" gives a more realistic idea about the spectral envelope associated to the observed emissions. The spectral envelope (i.e. "maximum-curve") is used hereafter to estimate the intensity level variations.

\subsection{Combination of ELF/VLF emissions and German transmitter signal}

The interesting results of Molchanov et al. (2006) are reconsidered in this section. First we start to check the outcomes of this previous paper in the case of seismic events which occurred in the year 2004 in Greece (23 November), in Italy (24 November and 5 December), and in the Adriatic sea (25 November). We study the intensity level variation of the DEMETER observed signal at the frequency of $16652.5 \mathrm{~Hz}$ which is the closest frequency to the German transmitter signal $(f=16560 \mathrm{~Hz})$. Afterward we select and analyze arbitrarily ELF/VLF ionospheric frequencies and combine them to the transmitter signal variations.

\subsubsection{Investigated time interval}

We select the period from 15 November to 17 December 2004. This leads to analyze the signal variation one week before the first seismic event, on 23 November and 10 days after the fourth EQs on 5 December. We limit our study to this time interval because: (a) the two first weeks of November 2004 are not taken into consideration because of an intense geomagnetic activity mainly on 9 and 10 November 2004, and (b) a data gap (no observations) in the end of December (from 18 to 25 December 2004).

\subsubsection{Natural and transmitter signals as recorded over Adri- atic seismic region}

Using the data processing method, as described in the previous subsection, we study the intensity variation of arbitrary ELF/VLF frequencies and of the German transmitter. Table 1 lists for each frequency (given in the first column) the different phases with the corresponding: (a) averaged intensity levels (expressed in $m \mathrm{~V}^{2} \mathrm{~m}^{-2} \mathrm{~Hz}^{-1}$ ) and (b) time intervals. It is clearly seen in Fig. 3 that transmitter signal intensity level is lower and higher before and after the EQ 


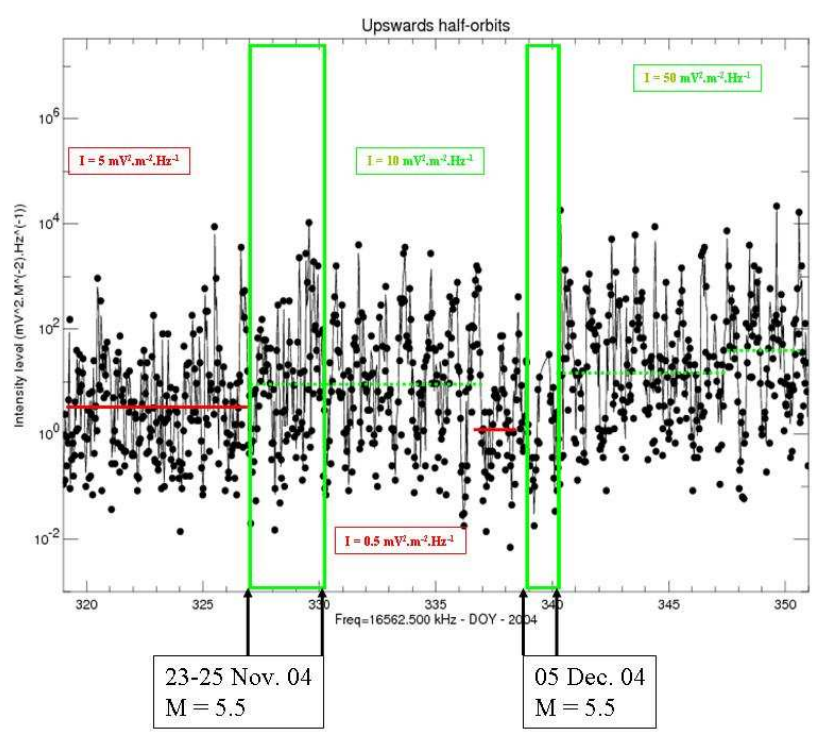

Fig. 3. Variation of the DEMETER observed signal at the frequency of $16652.5 \mathrm{~Hz}$ (the closest frequency to the German transmitter signal $16560 \mathrm{~Hz}$ ) versus the day of the year 2004 (from 15 November to 17 December 2004.). The EQs period are indicated by green boxes. The intensity levels before and after EQ occurrence are shown by red line and green dashed line, respectively.

occurrence, respectively. This is in agreement with the results of Molchanov et al. (2006). It is principally the case three days before EQ of 5 December where one notes a rapid decrease of intensity level to about $0.5 \mathrm{mV}^{2} \mathrm{~m}^{-2} \mathrm{~Hz}^{-1}$, and an increase to $10 \mathrm{mV}^{2} \mathrm{~m}^{-2} \mathrm{~Hz}^{-1}$ just after EQ. Figures 4 and 5 show similar behavior variation of ELF/VLF intensity levels which are summarized in Table 1 . It is interesting to note that the intensity level "after-to-before" EQ ratios are 150, 60 and 20 for the closest frequency $(16652.5 \mathrm{~Hz})$ to transmitter signal $(16560 \mathrm{~Hz})$, and at ELF/VLF frequencies $4804.688 \mathrm{~Hz}$ and $3867.188 \mathrm{~Hz}$, respectively (see Table 1). It is evident from this result that the frequency associated to the transmitter signal is more disturbed or attenuated than the natural ionospheric ELF/VLF emissions. However both show similar behavior.

\section{Discussion}

We investigate in this study the variation of the intensity levels of ELF/VLF ionospheric emissions and transmitter signals emitted from a ground-based station in Germany. Both electromagnetic radiations (naturel and artificial) have been detected and recorded by the ICE experiment onboard the DEMETER micro-satellite. Following the work of Molchanov et al. (2006) we re-investigate the behavior of natural ELF/VLF ionospheric signals over the seismic Adriatic region. We show in our analysis that the decrease of transmitter signal levels a few days before EQ occurrence is
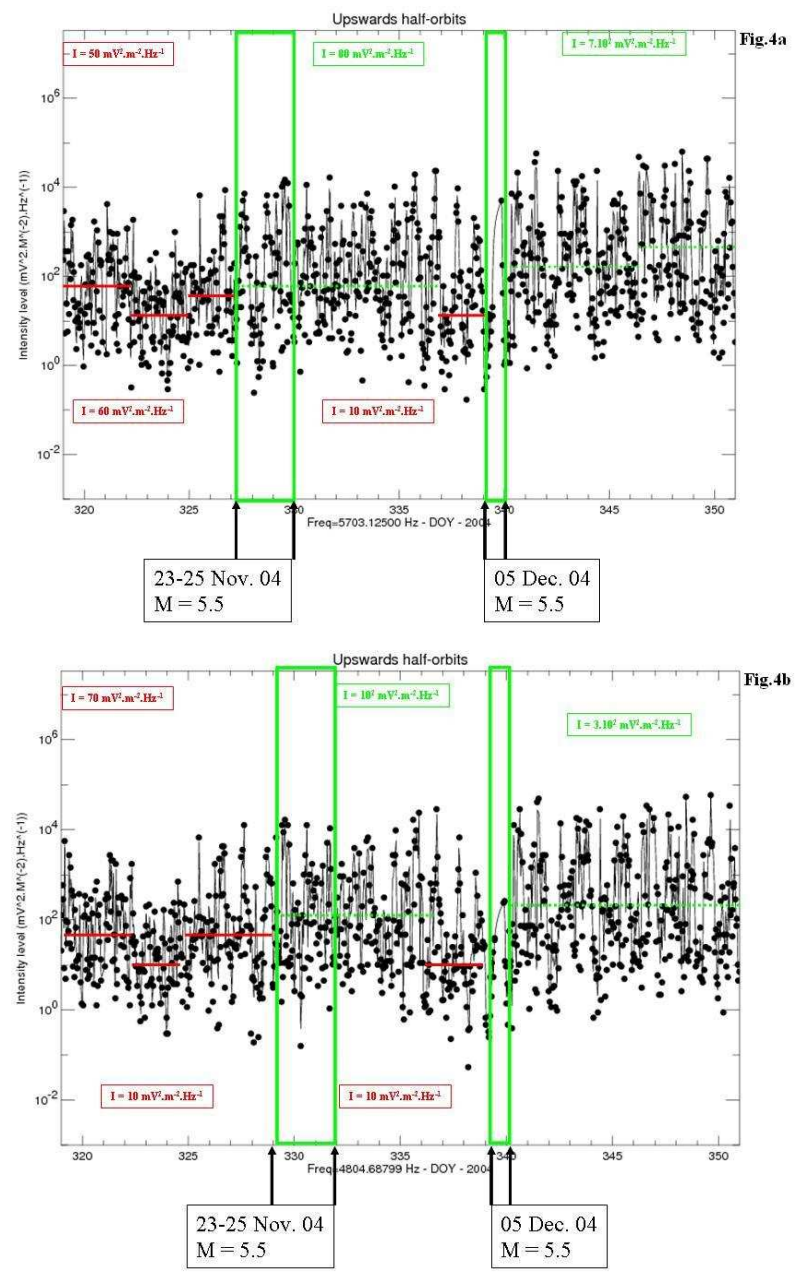

Fig. 4. Like in Fig. 3 for the frequencies $5703.125 \mathrm{~Hz}$ (Fig. 4a) and 4804.688 Hz (Fig. 4b).

real, and this confirm the Molchanov et al. (2006) results. More unexpected outcome from our study is to find that also the natural ionospheric emissions show similar behavior, like the transmitter signal. In the following we attempt to discuss the origins of this intensity level disturbance.

\subsection{Ionospheric disturbance due to seismic precursor effect}

Molchanov et al. (2006) proposed the atmospheric gravity waves (AGWs) as a mechanism of the origin of VLF transmitter signal disturbances. The authors considered that the disturbance is related to an upward energy flux of AGWs which are induced by the gas-water release from the EQ preparatory region (Liperovsky et al., 2000; Molchanov, 2004). The combination of ELF/VLF and transmitters signals show (see Figs. 3, 4 and 5) similar behavior. This means that the AGWs disturb the transmitter signals, and also the natural ELF/VLF emissions. Therefore the decrease of the intensity levels before the EQ occurrence are similar despite 
Table 1. Time phases of intensity level variations for the DEMETER observed signal at the frequency of $16652.5 \mathrm{~Hz}$ (the closest frequency to the German transmitter signal $16650 \mathrm{~Hz})$, and natural VLF ionospheric emissions $(f=5703.125 \mathrm{~Hz}, f=4804.688 \mathrm{~Hz}, f=3867.188 \mathrm{~Hz}$, $f=1562.500 \mathrm{~Hz}$ ) before and after EQs occurrences.

\begin{tabular}{|c|c|c|c|c|c|c|c|c|c|c|c|}
\hline \multirow[b]{2}{*}{ Freq. (Hz) } & \multirow[t]{2}{*}{ Figure } & \multicolumn{2}{|r|}{ Phase 1} & \multicolumn{2}{|r|}{ Phase 2} & \multicolumn{2}{|c|}{ Phase 3} & \multicolumn{2}{|c|}{ Phase 4} & \multicolumn{2}{|c|}{ Phase 5} \\
\hline & & $I$ & Period & $I$ & Period & $I$ & Period & $I$ & Period & $I$ & Period \\
\hline 16652.5 & Fig. 3 & 5 & 15-23 Nov & 10 & 23 Nov-3 Dec & 0.5 & 3-5 Dec & 0.3 & 5-6 Dec & 45 & 6-17 Dec \\
\hline 5703.125 & Fig. $4 \mathrm{a}$ & 45 & $15-23 \mathrm{Nov}$ & 80 & 23 Nov-3 Dec & 10 & 3-5 Dec & 8 & 5-6 Dec & 140 & 6-17 Dec \\
\hline 4804.688 & Fig. 4b & 60 & $15-23 \mathrm{Nov}$ & 100 & 23 Nov-3 Dec & 10 & 3-5 Dec & 5 & 5-6 Dec & 300 & 6-17 Dec \\
\hline 3867.188 & Fig. $4 \mathrm{c}$ & 40 & $15-23 \mathrm{Nov}$ & 100 & 23 Nov-3 Dec & 20 & 3-5 Dec & 10 & 5-6 Dec & 200 & 6-17 Dec \\
\hline 1562.500 & Fig. $4 d$ & 50 & $15-23 \mathrm{Nov}$ & 80 & 23 Nov-3 Dec & 10 & 3-5 Dec & 8 & 5-6 Dec & 80 & 6-17 Dec \\
\hline
\end{tabular}
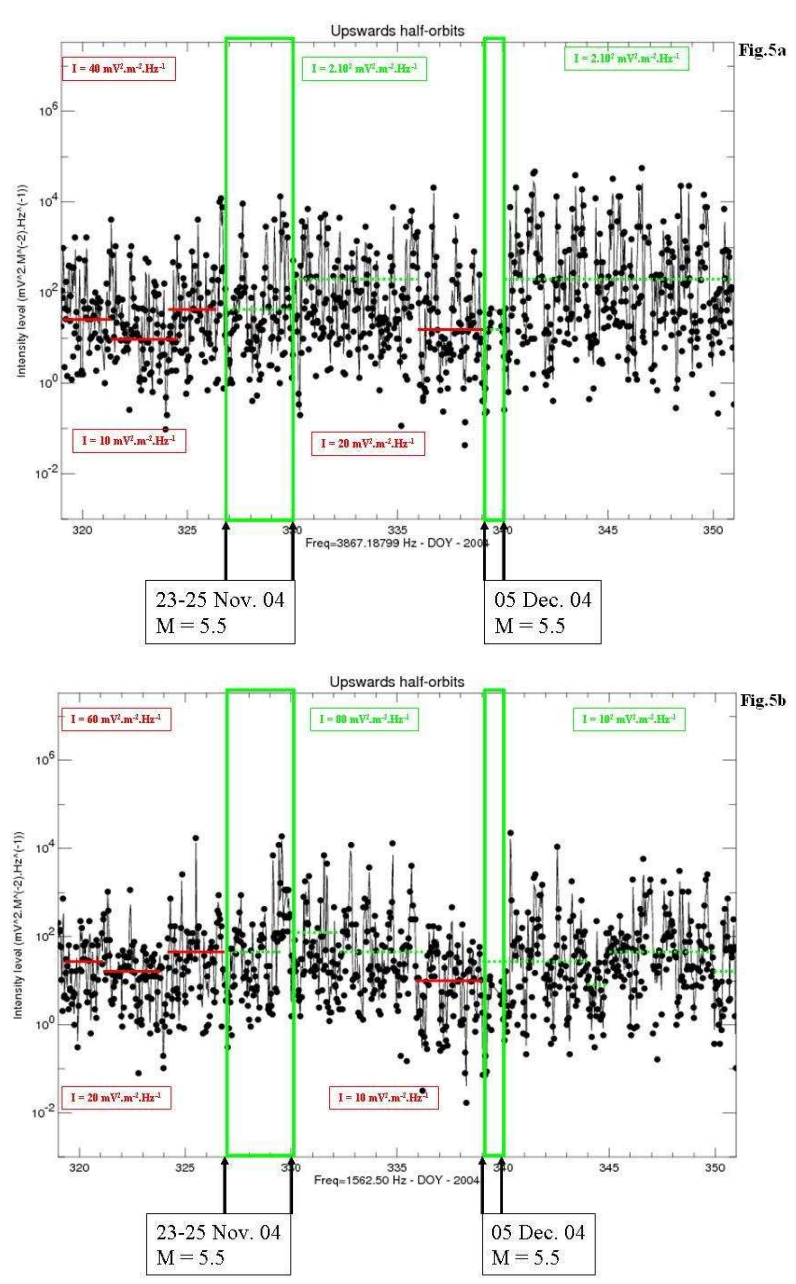

Fig. 5. Like in Fig. 3 for the frequencies $3867.188 \mathrm{~Hz}$ (Fig. 5a) and $1562.500 \mathrm{~Hz}$ (Fig. 5b).

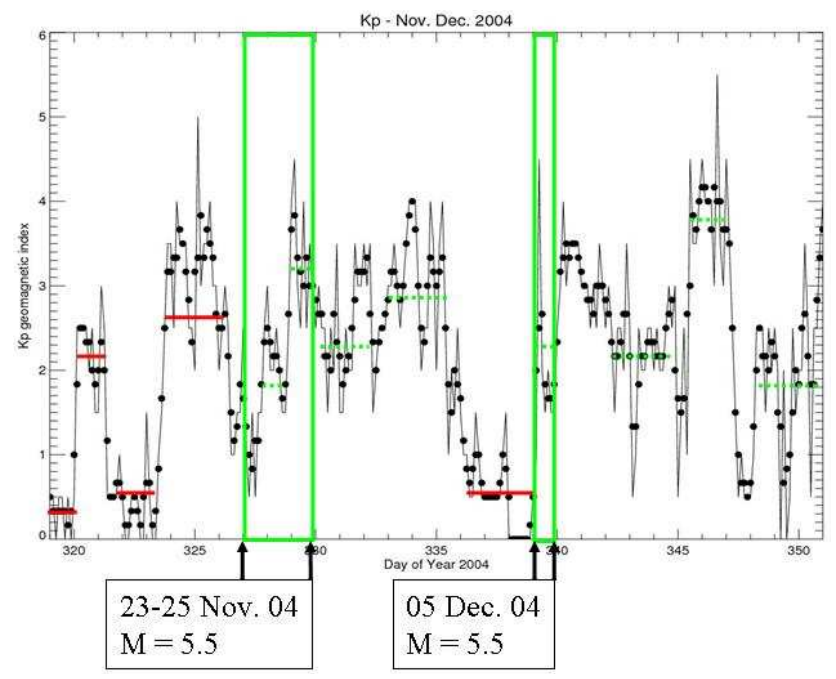

Fig. 6. Kp-index variation versus the day of the year 2004 (from 15 November to 17 December 2004.). The EQs period are indicated by green boxes. The intensity levels before and after EQ occurrences are shown by red line and green dashed line, respectively.

different origin of observed signals. On the other-hand, the efficiency of the AGW mechanism is significant because of its effect on a large frequency bandwidth (from $1 \mathrm{kHz}$ to $20 \mathrm{kHz}$ ).

\subsection{Ionospheric disturbance due to geomagnetic activity}

A second possible origin of the signal level disturbances, before the seismic occurrence, could be attributed to an geomagnetic activity. Figure 6 shows the variation of the Kpindex for the investigated time interval. The average value of the $\mathrm{Kp}$-index is found to be of about $\sim 2$ before the occurrence of the first EQ (i.e. in 23, 24, 25 November 2004), and it decreases during the seismic events. Afterward the $\mathrm{Kp}$-index is, on average, in the order of 2.5 in the time interval from 26 November to 1 December 2004. Few days before the second EQ (5 December 2004), the Kp-index is suddenly decreasing to a value of about 0.5 . During and after 
this second EQ, the Kp-index value increases, on average, to 2.5. When combining the ELF/VLF emissions and Kp-index variations for the investigated period, one finds that different and similar behaviors are observed during the occurrence of the first (mainly in November 2004) and second (beginning of December 2004) EQs, respectively. As shown in the pervious section (see in Figs. 3 and 4), a decrease of the intensity levels, i.e. of the ionospheric ELF/VLF emissions and transmitter signal, is clearly seen before occurrence of EQ of 5 December. It is very probable that the weak $\mathrm{Kp}$-index value has allowed us to see more easily the low intensity levels of ionospheric emissions and transmitter signal. This is not the case of the EQ of November which are preceded by a level of Kp-index higher than 2.

\section{Conclusions}

We investigate the ELF/VLF ionospheric emissions as observed by ICE experiment onboard DEMETER microsatellite. These emissions are combined to transmitter signal variations. Following the investigation of Molchanov et al. (2006) we confirm that over the seismic Adriatic region, the transmitter signal like the ELF/VLF ionospheric emissions have similar behaviors. Intensities associated to both emissions exhibit a decrease of their levels prior to the EQ occurrence. The origin of such ionospheric emissions could be associated to the AGWs gravity waves as suggested by Molchanov et al. (2006). However, it appears that the geomagnetic activity could be at the origin of such an effect or at least could disturb the ionosphere over the seismic region. From our study it comes that when the $\mathrm{Kp}$-index has a low value (less than one), the decrease of the ELF/VLF ionospheric emissions and transmitter signal levels could be observed and detected few days before the EQ occurrence. A clearness transparency of the ionosphere means principally a weak value of the Kp-index. Only in this case one could deduce the real effect of a seismic mechanism, like AGW mechanism, and how it disturbs the ionosphere a few days before the EQs occurrence.

Acknowledgements. This work is supported by the Austrian "Fonds zur Förderung der wissenschaftlichen Forschung" under project P20145-N16. We acknowledge support by the Austrian Academy of Sciences, "Verwaltungstelle für Auslandsbeziehungen". We express our thanks to the networking activity N3 (http://europlanet.oeaw.ac.at) of the European Planetology Network EuroPlaNet, for the support to organize in Graz (Austria) a workshop on 'Earthquakes: Ground-based and Space Observations', 1-2 June 2007.

Edited by: P. F. Biagi

Reviewed by: A. Rozhnoi and another anonymous referee

\section{References}

Bella, F., Biagi, P. F., Caputo, M., Cozzi, E., Della Monica, G., Ermini, A., Plastino, W., and Sgrigna, V.: Field strength variations of LF radio waves prior to earthquakes in Central Italy, Phys. Earth Planet. Inter., 105, 279-286, 1998.

Berthelier, J. J., Godefroy, M., Leblanc, F., Malingre, M., Menvielle, M., Lagoutte, D., Brochot, J.Y., Colin, F., Elie, F., Legendre, C., Zamora, P., Benoist, D., Chapuis, Y., Artru, J., and Pfaff, R.: ICE, the electric field experiment on DEMETER, Plant. Space Sci., 54, 456-471, 2006.

Biagi, P. F., Piccolo, R., Ermini, A., Martellucci, S., Bellecci, C., Hayakawa, M., Capozzi, V., and Kingsley, S. P.: Possible earthquake precursors revealed by LF radio signals, Nat. Hazards Earth Syst. Sci., 1, 99-104, 2001, http://www.nat-hazards-earth-syst-sci.net/1/99/2001/.

Biagi, P. F., Piccolo, R., Castellana, L., Ermini, A., Martellucci, S., Bellecci, C., Capozzi, V., Perna, G., Molchanov, O., and Hayakawa, M.: Variations in a LF radio signal on the occasion of the recent seismic and volcanic activity in Southern Italy, Phys. Chem. Earth, 29, 551-557, 2004.

Cussac, T., Ultre-Guerard, P. M. A, Buisson, F., Lassalle-Balier, G., Ledu, M., Elisabelar, C., Passot, X., and Rey, N.: The Demeter microsatellite and ground segment, Planetary and Space Science, 54, 413-427, 2006.

Fraser-Smith, A. C., Bernardy, A., McGill, P. R., Ladd, M. E., Helliwell, R. A., and Villardv Jr., O. G.: Low frequency magnetic field measurements near the epicenter of the Ms 7.1 Loma Prieta earthquake, Geophys. Res. Lett., 17, 1465-1468, 1990.

Gokhberg, M. B., Morgunov, V. A., Yoshino, T., and Tomizawa, I.: Experimental measurement of electromagnetic emissions possibly related to earthquakes in Japan, J. Geophys. Res., 87, 78247828, 1982.

Gufeld, I. L., Rozhnoi, A. A., Tyumensev, S. N., Sherstuk, S. V., and Yampolsky, V. S.: Radiowave disturbances in period to Rudber and Rachinsk earthquakes, Phys. Solid Earth, 28(3), 267-270, 1992.

Hayakawa, M.: Whistlers, Chapt.7, in: Handbook of Atmospheric Electrodynamics, edited by: Volland, H., vol. II, CRC Press, 155-193, 1995.

Hayakawa, M. and Molchanov, O. A.: Seismo Electromagnetics: Lithosphere-Atmosphere-Ionosphere Coupling, Terra Scientific Publishing Company (TERRAPUB), Tokyo, 2002.

Hayakawa, M. and Sazhin, S. S.: Mid-latitude and plasmaspheric hiss: A review, Planet. Space Sci., 40, 1325-1338, 1992.

Hayakawa, M., Kawate, R., Molchanov, O. A., and Yumoto, K.: Results of ultra-low-frequency magnetic field measurements during the Guam earthquake of 8 August 1993, Geophys. Res. Lett., 23, 241-244, 1996a.

Hayakawa, M., Molchanov, O. A., Ondoh, T., and Kawai, E.: The precursory signature effect of the Kobe earthquake on subionospheric VLF signals, J. Comm. Res. Lab., 43, 169-180, 1996b.

Liperovsky, V. A., Pokhotelov, O. A., Liperovskaya, E. V., Parrot, M., Meister, C.-V., and Alimov, O. A.: Modification of sporadic E-layers caused by seismic activity, S. Geophys., 21, 449-486, 2000.

Liu, J. Y., Chuo, Y. J., and Chen, Y. I.: Ionospheric GPS TEC perturbations prior to the 20 September 1999, Chi-Chi earthquake, Geophys. Res. Lett., 28, 1383-1386, 2001.

Maekawa, S., Horie, T., Yamauchi, T., Sawaya, T., Ishikawa, M., 
Hayakawa, M., and Sasaki, H.: A statistical study on the effect of earthquakes on the ionosphere, based on the subionospheric LF propagation data in Japan, Ann. Geophysicae, 24, 2219-2225, 2006.

Molchanov, O. A.: On the origin of low- and middle-latitude ionospheric turbulence, Phys. Chem. Earth, 29, 559-567, 2004.

Molchanov, O. A., and Hayakawa, M.: Seismo Electromagnetics and Related Phenomena: History and latest results, TERRAPUB, Tokyo, p. 189, 2008.

Molchanov, O. A. and Hayakawa, M.: Subionospheric VLF signal perturbations possibly related to earthquakes, J. Geophys. Res., 103, 17 489-17 504, 1998.

Molchanov, O., Rozhnoi, A., Solovieva, M., Akentieva, O., Berthelier, J. J., Parrot, M., Lefeuvre, F., Biagi, P. F., Castellana, L., and Hayakawa, M.: Global diagnostics of the ionospheric perturbations related to the seismic activity using the VLF radio signals collected on the DEMETER satellite, Nat. Hazards Earth Syst. Sci., 6, 745-753, 2006, http://www.nat-hazards-earth-syst-sci.net/6/745/2006/.

Molchanov, O. A., Kopytenko, Y. A., Voronov, P. M., Kopytenko, E. A., Matiashvili, T. G., Fraser-Smith, A. C., and Bernardy, A.: Results of ULF magnetic field measurements near the epicenters of the Spitak (Ms=6.9) and Loma Prieta (Ms=7.1)earthquakes: comparative analysis, Geophys. Res. Lett., 19, 1495-1498, 1992.

Muto, F., Yoshida, M., Horie, T., Hayakawa, M., Parrot, M., and Molchanov, O. A.: Detection of ionospheric perturbations associated with Japanese earthquakes on the basis of reception of LF transmitter signals on the satellite DEMETER, Nat. Hazards Earth Syst. Sci., 8, 135-141, 2008,

http://www.nat-hazards-earth-syst-sci.net/8/135/2008/.

Parrot, M.: Electromagnetic noise due to earthquakes, in: Handbook of Atmospheric Electrodynamics, edited by: Volland, H., vol. II., CRC Press, Boca Raton, FL, 95-116, 1995.

Parrot, M. and Lefeuvre, F.: Correlation between GEOS VLF emissions and earthquakes, Ann. Geophys., 3, 737-748, 1985, http://www.ann-geophys.net/3/737/1985/.
Parrot, M., Benoist, D., Berthelier, J.J., Blecki, J., Chapuis, Y., Colin, F., Elie, F., Fergeau, P., Lagoutte, D., Lefeuvre, F., Legendre, C., Leveque, M., Pincon, J. L., Poirier, B., Serana, H. C., and Zamora, P.: The magnetic field experiment IMSC and its data processing onboard DEMETER: Scientific objectives, description and first results, Planet. Space Sci., 54, 441-455, 2006.

Pulinets, S. A. and Boyarchuk, K. A.: Ionospheric Precursors of Earthquakes, Springer, New York., 2004.

Pulinets, S. A.: Seismic activity as a source of the ionospheric variability, Adv. Space Res., 22, 903-906, 1998.

Rozhnoi, A., Molchanov, O., Solovieva, M., Gladyshev, V., Akentieva, O., Berthelier, J. J., Parrot, M., Lefeuvre, F., Hayakawa, M., Castellana, L., and Biagi, P. F.: Possible seismo-ionosphere perturbations revealed by VLF signals collected on ground and on a satellite, Nat. Hazards Earth Syst. Sci., 7, 617-624, 2007, http://www.nat-hazards-earth-syst-sci.net/7/617/2007/.

Rozhnoi, A., Solovieva, M. S., Molchanov, O. A., and Hayakawa, M.: Middle latitude LF $(40 \mathrm{kHz})$ phase variations associated with earthquakes for quiet and disturbed geomagnetic conditions, Phys. Chem. Earth, 29, 589-598, 2004.

Sazhin, S. S. and Hayakawa, M.: Magnetospheric chorus emissions: A review, Planet. Space Sci., 40, 681-697, 1992.

Sardon, E., Rius, A., and Zarraoa, N.: Estimation of the transmitter and receiver differential biases on the ionospheric total electron content from global positioning system observations, Radio Science, 29, 577-586, 1994.

Slominska, E., Blecki, J., Parrot, M., and Slominski, J.: Satellite study of VLF ground-based transmitter signals during seismic activity in Honshu Island, Physics and Chemistry of the Earth, Phys. Chem. Earth, Parts A/B/C, doi:10.1016/j.pce.2008.06.016, in press, 2008.

Warwick, J. W., Stoker, C., and Meyer, T. R.: Radio emission associated with rock fracture: possible application to the great Chilean earthquake of 22 May 1960, J. Geophys. Res., 87, 28512859, 1982. 